\title{
Gravity and culture in foreign portfolio investment
}

\author{
Raj Aggarwal ${ }^{\mathrm{a}}$, Colm Kearney ${ }^{\mathrm{b}}$, Brian Lucey, ${ }^{\mathrm{c}, *}$ \\ ${ }^{a}$ College of Business Administration, University of Akron, Akron, Ohio 44325, USA \\ ${ }^{\mathrm{b}}$ Business School and Institute for International Integration Studies, Trinity College Dublin, \\ Dublin 2, Ireland \\ ${ }^{\mathrm{c}}$ Business School and Institute for International Integration Studies, Trinity College Dublin, \\ Dublin 2, Ireland, and Glasgow School for Business, Glasgow Caledonian \\ University Cowcaddens Road Glasgow G4 OBA Scotland, UK
}

This Version: August 312011

FORTHCOMING: Journal of Banking and Finance

\begin{abstract}
Using panel regression estimates from the IMF's CPIS survey of foreign debt and equity portfolios across 174 originating and 50 destination countries from 2001 to 2007, we clarify the role of culture and extend the set of cultural variables that have been investigated in gravity models of foreign portfolio investment (FPI). Incorporating Hofstede's cultural dimensions of individualism, masculinity, power distance and uncertainty avoidance, we show how cultural traits in both originating and destination countries, as well as the cultural distances that separate them, interact with geographic distance and other gravity variables to determine global FPI patterns. We find hitherto unreported effects and show that while gravity always deters FPI, aspects of culture and cultural distance can offset this by supporting FPI.
\end{abstract}

JEL classification: F21; F23 ; F37 ; G15

Keywords: FPI; Home bias; Culture; Gravity models

\footnotetext{
* Corresponding author. Tel. : +35318961552; fax : +35316799503.

Email addresses: aggarwa@uakron (R. Aggarwal), colm.kearney@tcd.ie (C. Kearney), blucey@tcd.ie (B. Lucey).
} 


\section{Introduction}

The gravity model ${ }^{1}$ of international trade is well established in the international business, economics and finance literatures. In international economics, it has become the dominant empirical model of trade flows ${ }^{2}$, and in international business, it has been applied to patterns of firm-level internationalisation, foreign market entry, international strategy, and the effects of culture on human resources, management and marketing ${ }^{3}$. In international finance, studies of equity market integration, foreign direct investment (FDI), foreign portfolio investment (FPI), intra-bank credit flows, and international mergers and acquisitions (M\&A) have used the gravity model $^{4}$. It is widely recognised, however, that the distance variable in gravity models, which proxies for a range of information, transaction, and other trading costs, does not fully capture these costs. This contributes to the so-called 'missing trade' problem (Trefler, 1995 et seq), whereby the volume of international trade is lower than expected, and to the 'home bias' puzzle (Lewis, 1999 et seq), whereby investors hold fewer foreign assets than seems justified by the available diversification benefits. It follows that there must be additional costs or other effects that are imperfectly captured by the distance variable in gravity models. In seeking to identify these other costs and effects, researchers have extended the basic gravity model by including variables such as regional trade and investment agreements; property rights, legal enforcements and restrictions; institutional strength; country, currency and political risk; security, delay effects and governmental controls; corruption and the rule of law; violence and war; and cultural effects such as language, legal system origin, religion, trust, and various components of Hofstede's (2001) cultural dimensions and Kogut and Singh's (1988) cultural distance.

Although Senior (1827) and Cairnes (1874) recognised long ago that familiarity with trading partners' language, institutions, social customs and religion are important determinants of trade in addition to geographical proximity, the inclusion of cultural variables in gravity models of 
international trade and finance is relatively recent (Anderson, 2000; Lewer and Van den Berg, 2007). When culture has been included, it has most frequently been interpreted along traditional economic lines as contributing to the costs of doing business by raising informational asymmetries and transaction costs, rather than as a separate influence that stems from societal differences in how people view the world, how they interact with others, and how they pursue the goals they consider to be appropriate.

Advances in the measurement of culture (Schwartz and Sagiv, 1995; Inglehart, 1997; Hofstede, 2001) and the Globe project (House et al., 2002) have spawned many applications and insights of relevance to financial decision-making. Disciplines such as anthropology, history and philosophy (House et al., 2002); genetics (Madox et al., 1984; Cesarini et al., 2010); and psychology (O'Grady and Lane, 1996) contribute to our understanding of the determinants of culture. National culture in turn influences the infrastructure upon which financial decisionmaking occurs - including the structure of markets and institutions (Kirkman, Lowe and Gibson, 2006; Aggarwal and Goodell, 2009a,b); accounting conventions and practices (Nobes, 1992) and systems of corporate governance (Bushman et al., 2004). These factors lie behind the costs that are proxied by the many controls that feature in gravity models, and in this sense, the standard gravity model already incorporates cultural effects.

Our purpose in this paper is to clarify and conceptualise more broadly how culture shapes global FPI patterns independently from the traditionally conceived gravity effects. Cultural effects in gravity models should be more completely conceived as additional to and distinct from the traditional informational asymmetry and transaction cost effects. In the theoretical world of mainstream economics and finance, fully-informed, rational, representative agents with identical beliefs and preferences optimally respond to asymmetric information, agency costs and moral hazard by seeking contracts that align the interests of all contracting parties. Because contracts are 
incomplete due to the impossibility of specifying all contingencies, however, they frequently have to rely on customary practices, social mores and ethics - which collectively form part of culture. In the world of behavioural international finance, cultural traits such as assertiveness, competitiveness, decisiveness, emotional expression, family cohesiveness, tolerance of inequality, group loyalty, inclusiveness, respect for tradition and social responsibility can be important determinants of financial decision-making alongside the long-recognised orientations with respect to return, risk and time. These dimensions of culture shape the core belief systems and values of heterogeneous agents from divergent cultures in ways that cannot be encompassed within the representative agent framework, and point instead to financial decision-making commensurate with the mental frames, judgemental heuristics and bounded rationality of Tversky and Kahneman (1974), Thaler (1993), Shefrin (2001) and de Bondt et al (2010). Studying global FPI patterns in this way recognises how cultural differences lead to internationally heterogeneous agents in the same way as divergent beliefs and preferences define heterogeneous investors in the recent withincountry asset pricing and portfolio theory of Hansen (2007), Bhamra and Uppal (2010) and Stiglitz (2010). It can also guide and inform investors, fund managers and regulators about how the interplay of divergent cultural traits drives observed FPI patterns, and how problems such as home-bias and regulatory arbitrage can be managed and mitigated if not resolved.

Theoretical modelling of heterogeneous agents with divergent beliefs, preferences and values is at an early stage, and our contribution to the literature on the role of culture in FPI is empirical in nature. We examine an extended set of national cultural traits alongside international cultural distances within gravity models of cross-border holdings of debt and equity in a manner that explicitly differentiates the role of culture from the standard gravity effects. Using the International Monetary Fund's (IMF) Coordinated Portfolio Investment Survey (CPIS) across 174 originating and 50 destination countries for the period 2001-2007, we conduct a series of panel 
estimates to clarify the roles and effects of three sets of variables that have been used in existing studies: the standard gravity variables that proxy for transport and transaction costs, institutional strength and informational asymmetry variables, and cultural variables. We control for the standard gravity, institutional strength and informational asymmetry effects using the geographic distance between countries, economic growth differentials, market development, corporate accounting quality, investor protection and country risk. Our cultural variables include language, legal system origin, religion, Hofstede's (2001) dimensions of degree of individualismcollectivism, masculinity-femininity, power distance and uncertainty avoidance, and Kogut and Singh's (1988) aggregate and disaggregated cultural distances based on Hofstede's cultural characteristics. We use the Hofstede (2001) cultural dimensions because they are widely known, commonly used, readily available for multi-country studies, and as Taras, Rowney and Steel (2009) show, they can encompass over 90 percent of the other measures that have been proposed. Our research methodology is designed to carefully separate the effects of culture from the other gravity variables in order to discern the extent to which they contribute separately identifiable explanatory power. We show that controlling for the standard gravity and institutional strength variables, cross-border FPI patterns are significantly determined by cultural characteristics in both the originating and destination countries - as well as by the cultural distances between them.

Our paper builds on the work of Daude and Fratzscher (2006), Guiso, Sapienza and Zingales (2009), Aviat and Coeurdacier (2007), Lane and Milesi-Ferretti (2008), Beugelsdijk and Frijns (2010) and Lucey and Zhang (2010). In studying how the degree of trust between European countries influences trade, FDI and FPI, Guiso, Sapienza and Ginzales (2009) examined an extensive set of control variables including information costs (geographic distance, shared border, shipping costs, commonality of language, shared legal origin, and relevant newspaper articles), and cultural proxies (ethnic and somatic distance, common linguistic roots, religious similarity, 
and history of war). They found that although gravity has limited effect on trust, the sharing of common legal origin, linguistic roots and religion promotes trust, while somatic distance, income differentials and years at war reduce trust. Trust, in turn, raises FDI and FPI, and gravity deters FDI but not FPI. In emerging markets, Lucey and Zhang (2010) showed that controlling for a traditional set of gravity variables (including location within the same region; market size, GDP growth and trading links; and shared legal system and origin), countries with similar religion and less Kogut-Singh (1988) cultural distances between them tend to have higher equity market correlations.

Our paper builds most closely on Beugelsdijk and Frijns's (2010) study of how culture contributes to the home bias puzzle. Using a large sample of domestic and foreign equity holdings of mutual funds in 26 countries that invested in a broader set of 48 countries in 1999 and 2000, these authors specified their estimating equations to explain the log ratio of a country's actual holdings relative to its optimal holdings according to the capital asset pricing model (CAPM). Their set of controls included host country attractiveness (transaction and capital costs and controls, tax levels, economic growth, per capita GDP and stock market development); regional arrangements (trade agreements, market unions and country fixed effects); risk and return profiles (lagged returns and correlations); and familiarity effects (common language, shared common law, and geographic distance). Using Hofstede's (2001) measures of individualism and uncertainty avoidance along with Kogut and Singh's (1988) aggregate measure of cultural distance, they found in their full sample that common language and individualism in the home country raises international equity holdings. They also found that greater uncertainty avoidance in the home country deters international equity holdings, and that cultural distance is not statistically significant. Their sub-samples include developed and emerging host countries, and cultural distance is correctly signed and significant in the former. 
Our analysis extends this literature by expanding the set of cultural characteristics that have been applied to originating and destination countries in gravity FPI models of debt and equity. By including both aggregate and disaggregated Kogut-Singh measures of cultural distance in our models, we show how the different dimensions of cultural distance interact with geographic distance in shaping cross-country FPI patterns. Although aggregate Kogut-Singh distance always interacts negatively with geographic distance to deter both debt and equity FPI, this does not apply universally to its constituent parts. We also find strongly significant hitherto unreported cultural effects. The existence of common language and religion between financial trading partners counteracts the gravitational forces of geographic and cultural distances, and these effects are greater for cross-border equity than debt. Countries that are less risky in terms of their overall political, economic and financial performance tend to participate more fully in cross-border FPI, but this propensity to reduce risk by diversifying internationally is not influenced by cultural attitudes to risk. In FPI originating countries, the degree of masculinity positively influences international diversification with debt more than twice as much as with equity FPI, and the degree of individualism positively influences equity holdings almost three times as much as debt. In FPI destination countries, higher (lower) degrees of masculinity, individualism and power distance tend to raise (reduce) cross-border debt and equity holdings by similar amounts. Overall, our paper points to the importance of separating the measurement and effects of gravity and culture - gravity always deters FPI, aggregate cultural distance interacts directly with geographic distance to further deter FPI, but individual aspects of culture and cultural distance can counteract these forces to promote FPI.

The remainder of our paper is structured as follows. In section 2, we present and describe our financial data, our gravity data including our controls for institutional strength and information asymmetry, and our extensive set of cultural variables. In section 3, we describe our methodology 
and formalise our testing models and procedures. Section 4 contains our findings. In section 5, we summarise our main findings and draw together conclusions.

\section{Data and methodology}

\subsection{Data}

Our main data source of international portfolio positions is the IMF's annual CPIS survey of the aggregate debt and equity positions of countries and states along with the foreign asset portfolios of reporting entities with respect to each other. These data are available on an end-ofyear basis for each of the years 2001-2007. The portfolios are measured in \$US millions and disaggregated into long-term debt, short-term debt, and equity. To avoid problems with volatile short-term financial flows, we focus on long-term debt and equity. We eliminate all transactions involving dependent states or entities ${ }^{5}$, small offshore financial centres ${ }^{6}$, international organizations, confidential transactions, unallocated data, and cases where there is insufficient data $^{7}$. The definitions and data sources of all variables employed in our empirical tests are provided in Table 1. Table 2 provides summary descriptive statistics for each.

Tables 1 and 2 here

Although the concept of culture has been around for centuries, it is only since the mid- $20^{\text {th }}$ century that researchers have begun to systematically define and measure it, and to collect data on it across countries and over time. Taras, Rowney and Steel (2009) review 121 approaches to measuring culture, showing that it is a complex, multi-level construct defined by assumptions, values and practices. The most commonly used measure is from Hofstede (2001) who describes four $^{8}$ essential but orthogonal dimensions of national culture: individualism (Indv), masculinity (Masc), power distance (Powd) and uncertainty avoidance (Unca). Each of these dimensions, and combinations of them, has the potential to influence financial decision-making - particularly in 
the realm of FPI which frequently occurs across national cultures. In addition to these, we include common language, legal system origin, religion, the Kogut and Singh (1988) measure of cultural distance; and the decomposition of the latter into the four Hofstede (2001) components.

A society's degree of individualism refers to the extent that its members tend to be loosely connected and responsible for their own wellbeing, rather than being closely connected within cohesive groups that offer protection in return for loyalty in more collectivist societies. High individualist societies emphasize the importance of individual motivation and individual rather than group decision-making, with compensation based on the individual's contribution rather than on the group's performance. Recent work by Gorodnichenko and Roland (2010) suggests that countries that demonstrate higher levels of individualism tend to grow faster and are wealthier, so ceteris paribus, greater distance in individualism tends to associate with more diverse sets of investment opportunities and greater wealth disparity.

A society's degree of masculinity measures the extent to which it emphasizes and rewards the male characteristics of assertiveness, competition and success rather than the female characteristics of nurturance and support, and it also embodies the extent to which societal members are expected to manifest and perform these roles. Societies that score highly on masculinity tend to exhibit behaviour towards achievement rather than solidarity, confrontation rather than cooperation, and intellectual independence rather than moral obligation. Although the degree of masculinity does not correlate with the other dimensions (except uncertainty avoidance, with a statistically significant positive value in wealthier countries and a marginally significant negative value in poorer countries), this is the least accepted of Hofstede's cultural dimensions because it is difficult to distinguish its implied behavioural traits.

The concept of power distance was developed by Mulder (1977) and built upon by Hofstede (2001) to refer to the differential weights that societies assign to inequality in power, 
status and wealth, and the extent to which its members expect power to be unequally distributed. House et al. (2002) trace the roots of this cultural dimension to Plato's argument for the merits of an elite ruling class in $4^{\text {th }}$ century BC Athens, to Confucian and Hindu philosophy that respects tradition and seniority, to the Hobbesian $17^{\text {th }}$ century recognition of the need for checks on individual greed and ambition. Low power distance cultures tend to disseminate information broadly, to provide wide access to education and resources for personal development, to exhibit substantial social mobility, and to encourage discussion and critique in corporate decision-making. By contrast, high power distance cultures tend to exhibit localised information, unequal access to education and resources, corporate decision-making by senior management with limited input from subordinates, and limited social mobility. Catholicism, Confucianism, Hinduism and Islam tend to be high in power distance, while Buddhism and Protestantism tend to be low.

The concept of uncertainty avoidance is familiar to financial analysts and researchers, particularly given the many tools that have been designed to manage risk and to financially engineer preferred combinations of risk and reward. Initiated by Cyert and March (1953), the uncertainty avoidance dimension in national culture was developed by Hofstede (2001) to capture the anxiety that people feel when exposed to ambiguity and uncertainty. Societies tend to construct three coping mechanisms to deal with uncertainty: technology (which helps us cope with uncertainties of nature), law (which helps us cope with uncertainties caused by the behaviour of other people) and religion (which helps us cope with uncertainties we cannot otherwise defend against). High uncertainty avoidance societies tend to exhibit more complete accounting disclosures, less risk-taking, lower ambition for personal advancement, greater resistance to change, and higher average age in senior positions.

Table 3 provides the measures of these cultural dimensions in a selection of 30 countries, and for a set of 10 cultural groupings (Ronen and Shenkar (1985), House et al (2004)) including 
Anglo, Confucian Asian, Eastern European, Germanic European, Latin American, Latin European, Middle Eastern, Nordic European, South Asian and Sub-Saharan African. Anglo includes Australia, Canada, Ireland, New Zealand, South Africa and the UK. Confucian Asian includes China, Hong Kong, Japan, Singapore, South Korea and Taiwan. Eastern European includes Albania, Georgia, Greece, Hungary, Kazakhstan, Poland, Russia and Slovenia. Germanic European includes Austria, Germany, the Netherlands and Switzerland. Latin European includes France, Israel, Italy, Portugal, Spain and Switzerland. Middle Eastern includes Egypt, Kuwait, Morocco, Qatar and Turkey. Nordic European includes Denmark, Finland and Sweden. South Asian includes India, Indonesia, Iran, Malaysia, the Philippines and Thailand. The Latin America and sub-Saharan African groupings are self evident.

\section{Table 3 here}

Looking first at the cultural groupings at the bottom of the Table, they are least differentiated with respect to their degrees of individualism, with a range of 29 percent around the mean score of 3.83. Anglo, Nordic and Germanic European cultures exhibit the highest degrees of individualism, while Latin America, Southeast and Confucian Asian are the most collectivist cultures. Looking next at the degree of masculinity, the range of 60 percent is the greatest of the cultural dimensions, being highest for Confucian Asian and lowest for Nordic European which is 50 percent below the mean score. In the absence of Nordic European, the range declines to 10 percent. The power distance dimension has a range of 33 percent, being highest in South Asian, Middle Eastern, Latin American, and Confucian Asian cultures, and lowest in Nordic and Germanic Europe. The range of scores for uncertainty avoidance is 40 percent, being highest for Eastern and Latin European, Middle Eastern and Latin American, and lowest for Confucian Asian followed by Nordic European and Anglo. The individual country scores mostly corroborate what we see in the cultural groupings. The United States scores highly on individualism and is amongst 
the group of lowest risk avoiding countries. Singapore is amongst the most collectivist countries and is not risk avoiding.

Amongst the most differentiated cultures are Anglo, Germanic and Nordic European, which exhibit the greatest degrees of individualism coupled with least power distance, while two of these (Germanic European being the exception) are also the most comfortable with ambiguity and uncertainty. While Eastern European culture is by far the most averse to uncertainty, it is midranked on all other dimensions. At the other extreme of uncertainty avoidance, Confucian Asian culture is the most comfortable with uncertainty and risk-taking, and it is also the most masculine and third most collectivist culture. Latin American culture is the most collectivist culture, and it also exhibits a high degree of power distance. The fundamental contribution of our paper is to demonstrate that controlling for geographic distance and other gravity variables that proxy for institutional strength and informational asymmetry, these cultural characteristics in different countries - together with the cultural distances that separate them - exert additional influences on global patterns of FPI in debt and equity that have not been hitherto recognised.

\subsection{Methodology}

Initial applications of the gravity model to FPI by Portes and Rey $(1998,2005)$ found that it performs at least as well in explaining financial asset trade as commodity trade. Interpreting the distance variable as proxying for transaction and transportation costs, informational asymmetries, currency risk and institutional differences, and noting that financial assets are weightless with low transaction costs relative to commodities, Portes and Rey (2005) surmised that distance should not significantly deter financial asset trade, particularly if investors seek international diversification benefits that generally rise with distance. Recognising that geographically close countries tend to be familiar with each other because of direct personal contact through business and tourism, 
because their people tend to learn each other's languages if different, and because of indirect contact through media coverage, Portes and Rey (2005) added other variables to capture information asymmetries and the efficiency of transactions, including the number of overlapping trading hours, the number of telephone calls between countries, foreign bank branches and the degree of financial sophistication. They conjectured and confirmed that insofar as distance acts as a proxy for information effects, more finely tuned proxies should reduce the role of geographic distance in their models.

Building on Portes and Rey (2005) and on the more recent work of Guiso Sapienza and Ginzales (2009), Beugelsdijk and Frijns (2010) and Lucey and Zhang (2010) who have extended the set of variables in gravity models to include aspects of culture, our methodology is designed to separately identify the roles of gravity, institutional strength and informational quality, while extending the set of cultural variables that have been hitherto included in gravity models of FPI. To do this, we investigate three sets of variables that apply to the originating country (superscript ' $O C$ '), the destination country (superscript ' $D C$ '), and to the distance between them. The first set of 3 variables in vector (1) contains the basic gravity variables including the geographic distance

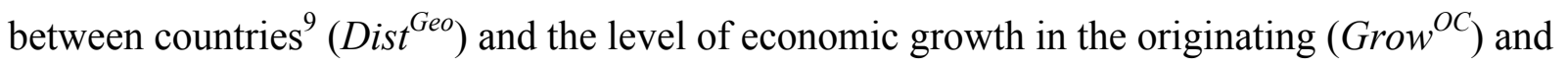
destination country $\left(\right.$ Grow $\left.^{D C}\right)$.

Gravity $=G\left(\right.$ Dist $^{\text {Geo }}$, Grow $^{O C}$, Grow $\left.^{D C}\right)$

Our second set of 10 variables in vector (2) captures variations in the degree of institutional strength and informational quality across countries, Instit. We include the degree of bond market development ( $B \operatorname{dev}^{O C}$ and $B d e v^{D C}$ ), the degree of equity market development ( 
$E d e v^{O C}$ and $E d e v^{D C}$ ), corporate accounting quality $\left(A c c q^{O C}\right.$ and $\left.A c c q^{D C}\right)$, investor protection ( $I n v p^{O C}$ and $\left.I n v p^{D C}\right)$ and country risk ( Risk $^{O C}$ and $\left.R i s k^{D C}\right)$.

$$
\begin{aligned}
\text { Instit }= & I\left(\operatorname{Bdev}^{O C}, \operatorname{Bdev}^{D C}, \operatorname{Edev}^{O C}, \operatorname{Edev}^{D C}, A c c q^{O C}, A c c q^{D C},\right. \\
& \left.\operatorname{Invp}{ }^{O C}, \operatorname{Invp}^{D C}, \text { Risk }^{O C}, \operatorname{Risk}^{D C}\right)
\end{aligned}
$$

Our third set of 16 variables in vector (3) contains the cultural variables. We first include the Kogut and Singh (1988) measure of cultural distance $\left(\right.$ Dist $\left.{ }^{K S}\right)$, which is an aggregate measure of the distance between cultures using Hofstede's (2001) four cultural characteristics. We then decompose this aggregate cultural distance into its four components including the distance between the originating and destination countries in terms of their degrees of individualism $\left(\right.$ Dist $\left.^{\text {Indy }}\right)$, masculinity (Dist ${ }^{\text {Masc }}$ ), power distance (Dist $\left.{ }^{\text {Powd }}\right)$, and uncertainty avoidance (Dist $\left.{ }^{\text {Unca }}\right)$. Having examined the role of cultural distance, we then turn our attention to the cultural characteristics within the originating and destination countries. We first include dummy variables for whether the originating and destination countries share common language (Clan), common legal system origin ( $\mathrm{Cleg}$ ) and common religion ( $\mathrm{Crel}$ ). We then add Hofstede's (2001) measures of the degree of individualism in the originating and destination countries (Indv ${ }^{O C}$ and $\operatorname{Indv}{ }^{D C}$ ), the degree of masculinity in both countries $\left(\mathrm{Masc}^{O C}\right.$ and $\mathrm{Masc}^{D C}$ ), the degree of power distance in both countries (Powd $d^{O C}$ and $P o w d^{D C}$ ) and the degree of uncertainty avoidance in both countries $\left(U n c a^{O C}\right.$ and $\left.U n c a^{D C}\right)$.

$$
\begin{aligned}
& \text { Culture }=C\left(\text { Dist }^{K S}, \text { Dist }^{\text {Masc }}, \text { Dist }^{\text {Indv }}, \text { Dist }{ }^{\text {Powd }}, \text { Dist }{ }^{\text {Unca }}, \text { Clan, Cleg, Crel, Masc }{ }^{\text {OC }},\right. \\
& \operatorname{Masc}^{D C}, \operatorname{Indv}{ }^{O C}, \operatorname{Ind} v^{D C}, \text { Powd }^{O C}, \text { Powd }^{D C}, U_{n c a^{O C}}, U_{n c a^{D C}} \text { ) }
\end{aligned}
$$


The inclusion of cultural identifiers in the originating and destination countries along with the cultural distances between these countries is analogous to the inclusion of gravity and institutional strength variables for each country alongside the geographical distance variable in standard gravity models of international trade. Furthermore, our testing methodology allows us to examine the extent to which, controlling for the standard gravity and institutional strength variables in vectors (1) and (2), cross-border FPI patterns are also determined by the cultural characteristics of the originating and destination countries as well as by the cultural distances that separate them.

Table 4 shows how cultural distance acts alongside physical distance to raise or reduce the overall (physical and cultural) distance between countries by presenting examples of the greatest and least physical, cultural, and overall distances from the full sample of 564 country pairs identified by the originating country for FPI flows. The physical distances are measured in thousands of kilometres in column (2). The cultural distances in column (4) are Kogut -Singh measures, and the combined physical and cultural distances in column (6) are the addition of the logs of physical distances plus the Kogut-Singh measure of cultural distances. In Panel A, columns (1), (3) and (5) provide all unique country pairs, with no individual country repeated, in the 25 country pairs with the greatest distances. Likewise, columns (1), (3) and (5) of Panel B provide all unique country pairs, with no individual country repeated, in the 25 country pairs with the least distances.

\section{Table 4 here}

Looking first at Panel A, we see in columns (1) and (2) that there are 4 most physically distant country pairs in the top 25 that do not repeat any country, and they are New Zealand Spain; Columbia - Malaysia; Brazil - Philippines; and Australia - UK. Looking at columns (3) 
and (4), however, we can see that none of these most physically distant country pairs is amongst the most culturally distant pairs. The latter include Japan - Sweden; Denmark - Mexico; Austria Malaysia; Greece - Singapore; Portugal - UK; and Norway - Philippines. When we combine both measures of distance in columns (5) and (6), we find that 5 of the most culturally distant pairs are also found amongst the most distant overall pairs. Cultural proximity can be expected to mitigate the gravitational effects of physical distance, particularly when the latter is great.

Looking next at Panel B, we can see in columns (1) and (2) that the most physically close country pairs are those that share land borders or are connected by bridges or tunnels. But we can also see from columns (3) and (4) that the culturally closest countries are often very distant physically, such as Australia - US; Brazil - Turkey; Chile - Portugal; and Argentina - Spain. Combining the physical and cultural distances in columns (5) and (6), it is intuitive that we are left with countries that are both physically contiguous and culturally close. Indeed, it is reassuring that our methodology reveals in column (6) eight very intuitive examples of the closest country pairs imaginable, Belgium - France; Norway - Sweden; Germany - Switzerland; Ireland - UK; Canada - US; Malaysia - Singapore; Greece - Turkey; and Denmark - Netherlands.

We can cast additional light on how cultural distance interacts with geographic distance using tree-structured, non-parametric classification analysis. We do this using the classification and regression tree (CART) methodology of Breiman et al. (1984) and Steinberg and Colla (1995). Using the full set of 564 country pairs of geographic, cultural and total distances that are summarised in Table 4, and supplementing this with the disaggregated Kogut-Singh cultural distances, we can numerically classify the data into self-identifying groups using regression tree analysis. This methodology does not require specification of a functional form, and the results are invariant with respect to monotone transformations such as logarithms, square roots or squares. 
The results are presented in Figure 1. Panel A categorises overall distances (measured as the sum of geographic and cultural distance) into their geographic and cultural constituents. Looking down from the top of panel A, we first decompose overall distance into low cultural distance on the left side (with 395 country pairs) and high cultural distance on the right side (with the remaining 169 country pairs. Looking further down the left side of Panel A, the low culturally distant country pairs are then decomposed into 116 low geographically distant country pairs and 279 high geographically distant pairs. The 116 cases on the bottom left of panel A include the countries that are least distant in both geographic and cultural distances presented in columns (5) and (6) of panel B of Table 4. Similarly, the 35 country pairs on the bottom right of panel A in Figure 1 contain the pairs presented in columns (3) and (4) of panel A of Table 4. Of particular note is that the overall distance in Panel A is split first into cultural rather than geographic distance, which indicates the potential relative importance of culture in gravity models of FPI.

Figure 1 here

Panel B shows how the Kogut-Singh cultural distances are decomposed into power (Powd), masculinity (Masc), individualism (Indv) and uncertainty avoidance (Unca) distances. The first decomposition here is amongst the low and high power distances which are shared almost equally at 273 and 291 country pairs. As we look further down the left side of panel B, the 273 low power distant pairs are divided into 217 low and 56 high masculinity distances. The former are then divided into 195 low and 22 high power distant pairs. Overall, our nonparametric classification-tree analysis shows in considerable detail how cultural distances interact with their geographic counterparts across the 564 pairs in our sample to yield clearly identifiable sets of country pairs in geographic-cultural distance. Of particular note here is that although the KogutSingh disaggregated distances are classified into groups that use all four of Hofstede's dimensions, 
cultural differences in power distance and degree of masculinity are more readily identifiable than for in individualism and uncertainty avoidance.

Combining this data with our full dataset of the CPIS information on long-term debt and equity holdings for 174 originating and 50 destination countries for 2001-2007, we now derive a series of panel estimates to arrive at our parsimonious models. Following standard practice in the literature, we specify our models in natural logarithms, and we estimate them using ordinary least squares (OLS) with White-corrected standard errors. We do not include country-pair fixed effects, because the distance variable which is fixed by construction captures these effects.

To implement our hierarchical testing methodology in which the outcome of the first two steps yields the set of gravity controls in our final estimating models that focus on the role of culture in FPI, we first estimate our benchmark gravity model using the vector of basic gravity variables in vector (1). The estimating equation for this model is as follows.

$$
F P I_{t}^{i}=\alpha_{0}^{i}+\alpha_{1}^{i} D_{i s t}^{G e o}+\alpha_{2}^{i} \text { Grow }^{O C}+\alpha_{3}^{i} \text { Grow }^{D C}+\varepsilon_{t}^{i}
$$

In this equation, $F P I_{t}^{i}$ denotes each destination country's holdings of either debt or equity (denoted by superscript $i=$ debt, equity) from each origination country, and $\varepsilon_{t}^{i}$ is the regression residual. Following the general-to-specific estimation strategy of Hendry (2000), we sequentially restrict this specification by dropping the statistically insignificant variables until we obtain our parsimonious Gravity vectors for debt and equity, which we designate by $\bar{G}^{i}$. We then introduce our institutional strength variables in the Inst vector (2) to form estimating equation (5).

$$
F P I_{t}^{i}=\beta_{0}^{i}+\bar{G}^{i}+\beta_{1}^{i} B d e v^{O C}+\beta_{2}^{i} B d e v^{D C}+\beta_{3}^{i} E d e v^{O C}+\beta_{4}^{i} E d e v^{D C}+\beta_{5}^{i} A c c q^{O C}
$$




$$
+\beta_{6}^{i} A c c q^{D C}+\beta_{7}^{i} \operatorname{Invp}{ }^{O C}+\beta_{8}^{i} \operatorname{Invp}{ }^{D C} \beta 9_{9}^{i} \operatorname{Risk}^{O C}+\beta_{10}^{i} \operatorname{Risk}^{D C}+\varsigma_{t}^{i}
$$

As before, we sequentially restrict this specification by dropping the statistically insignificant variables to obtain our parsimonious institutional strength vectors, $\bar{I}^{i}$. These parsimonious models then form the set of gravity and institutional strength controls that feature in our final set of models that incorporate the cultural variables from vector (3). The general form of these estimating equations is presented in (6).

$$
\begin{aligned}
& F P I_{t}^{i}=\gamma_{0}^{i}+\bar{G}^{i}+\overline{\mathrm{I}}^{i}+\gamma_{1}^{i} \operatorname{Dist}^{G e o} * \operatorname{Dist}^{K S}+\gamma_{2}^{i} \text { Dist }^{\text {Masc }}+\gamma_{3}^{i} \text { Dist }^{\text {Indv }} \\
& +\gamma_{4}^{i} \text { Dist }^{\text {Pond }}+\gamma_{5}^{i} \text { Dist }{ }^{\text {Unca }}+\gamma_{6}^{i} \text { Clan }+\gamma_{7}^{i} \text { Cleg }+\gamma_{8}^{i} \text { Crel }+\gamma_{9}^{i} \text { Masc }^{\text {OC }} \\
& +\gamma_{10}^{i} \operatorname{Masc}^{D C}+\gamma_{11}^{i} \operatorname{Ind} v^{O C}+\gamma_{12}^{i} \operatorname{Ind} d v^{D C}+\gamma_{13}^{i} \text { Powd }^{O C}+\gamma_{14}^{i} \text { Powd }^{D C} \\
& +\gamma_{15}^{i} U_{n c a^{O C}}+\gamma_{16}^{i} U n c a^{D C}+\xi_{t}^{i}
\end{aligned}
$$

Setting $\gamma_{1}^{i} \ldots \gamma_{16}^{i}=0$ in (6) yields model (5) as a nested version that incorporates only the gravity and institutional strength variables without any cultural influences. To shed extra light on the interplay between geographic and cultural distances in determining global FPI patterns, we also estimate a simplified version of (6) that excludes all cultural variables except the aggregate Kogut-Singh measure of cultural distance. We follow Huang (2007) by including the aggregate cultural distance term, $\mathrm{Dist}^{K S}$, in multiplicative form in relation to geographical distance, Dist ${ }^{\mathrm{Geo}}$, to form the $\mathrm{Dist}^{\mathrm{Geo} *}{ }^{\mathrm{Dist}} \mathrm{K}^{K S}$ variable. Setting $\gamma_{2}^{i} \ldots \gamma_{16}^{i}=0$ in (6) then yields estimating equation (7).

$$
F P I_{t}^{i}=\gamma_{0}^{i}+\alpha_{1}^{i} \text { Dist }^{\text {Geo }}+\alpha_{2}^{i} \text { Grow }^{O C}+\alpha_{3}^{i} \text { Grow }^{D C}+\overline{\mathrm{I}}^{i}+\gamma_{1}^{i} \text { Dist }^{\text {Geo }} * \text { Dist }^{K S}+\zeta_{t}^{i}
$$




$$
=\gamma_{0}^{i}+\operatorname{Dist}^{G e o}\left(\alpha_{1}^{i}+\gamma_{1}^{i} \text { Dist }^{K S}\right)+\alpha_{2}^{i} \text { Grow }^{O C}+\alpha_{3}^{i} \text { Grow }^{D C}+\overline{\mathrm{I}}^{i}+\zeta_{t}^{i}
$$

Here, the $\alpha_{1}^{i}$ term captures the geographic distance effects on bilateral cross-border FPI holdings that are not captured by the remaining gravity and institutional strength variables in the $\bar{G}^{i}$ and $\bar{I}^{i}$ vectors. The $\gamma_{1}^{i}$ term then captures the extent to which the geographic distance effects are altered by cultural distance. Bearing in mind the interplay between geographic and cultural distances in Table 4, we expect a negative relation between cultural distance and FPI. If cultural distance is a significant deterrent to cross-border FPI holdings, the $\gamma_{1}^{i}$ term in (7) should be negatively signed and statistically significant. In this case, countries that are similarly distant geographically will, ceteris paribus, appear more distant to the extent that their cultures are different. We also expect this effect to be stronger for equity than for debt, because the former is based on more uncertain future cash flows, and because insolvency ranks debt obligations as primary and equity as the residual.

We complete our empirical analysis by setting the aggregate cultural distance parameter $\gamma_{1}^{i}$ $=0$ and including the remaining $\gamma_{2}^{\mathrm{i}} \ldots \gamma_{16}^{\mathrm{i}}$ parameters in (6) to examine the roles of the individual components of cultural distance and the cultural characteristics of the originating and destination countries in determining cross-border FPI patterns.

\section{Results}

\subsection{FPI, gravity and institutional strength}

Table 5 presents our parsimonious models for cross-border holdings of debt and equity that include all statistically significant gravity and institutional strength variables. To provide benchmark estimates of the effects of gravity in our models, columns (1) and (4) of the Table 
provide estimates for debt and equity FPI holdings using only the geographic distance variable $\left(\right.$ Dist $^{G e o}$ ) in model (4) while setting $\alpha_{0}^{\mathrm{i}}=\alpha_{1}^{\mathrm{i}}=\alpha_{2}^{\mathrm{i}}=\alpha_{3}^{\mathrm{i}}=0$. This benchmark gravity coefficient is correctly signed and statistically significant in both cases, with a larger coefficient of -1.91 for debt than the -1.66 coefficient for equity. Our estimates of equation (4) using the full gravity vector (1) are presented in columns (2) and (5) of the Table. The geographic distance variable changes very little in both equations. The coefficients on economic growth in the originating and destination countries $\left(\right.$ Grow $^{O C}$ and Grow $^{D C}$ ) are significant determinants of cross-border equity holdings, but neither are significant determinants of cross-border debt holdings.

Table 5 here

We next add the variables in our institutional strength Instit vector (2) to derive our parsimonious estimates of equation (5) for cross-border debt and equity FPI holdings in columns (3) and (6) of Table 5. The equations are well specified, with $R^{2}$ statistics explaining between 52 and 54 percent of the variation in cross-border FPI holdings. Looking across the rows of the Table, the coefficient signs along with their levels of significance are consistent for most variables in the equations for debt and equity, with all variables being significant in the equity equation and less being significant in the debt equation.

Looking first at the geographic distance variable, we can see that, consistent with previous studies such as Portes and Rey (2005), it declines to -1.26 and -0.99 for debt and equity respectively, but remains strongly significant when we introduce the other gravity and institutional strength variables. This is consistent with but somewhat larger than Daude and Fratzscher (2006) whose benchmark estimates of the distance coefficient for debt and equity are -0.8 and -0.7 ; Lane and Milesi-Ferretti (2008) whose distance coefficient on equity holdings is -0.6; Guiso et al (2006) whose distance coefficient in their instrumental variable general method of moments (IVGMM) estimate of their FDI model is -0.7; and Beugelsdijk and Frijns (2010) whose distance coefficient 
in their base model without culture is -0.7 . By focussing only on the gravity and institutional strength variables, while excluding the effects of culture, we find that a doubling of geographic distance leads to a 126 percent reduction in debt holdings and to a 99 percent reduction in equity holdings. The rate of economic growth in the origination and destination country continues to exert a significantly positive influence on cross-border equity holdings, with the greater effect coming from the originating country.

Looking next at the institutional strength variables, the extent of bond market development in the originating country exerts a positive and statistically significant effect on cross-border holdings of both debt and equity, with the coefficient of 3.07 for debt being intuitively greater than 2.02 for equity holdings. Interestingly, the extent of bond market development in the destination country does not influence cross-border debt holdings, but it raises equity holdings, with a coefficient of 0.73 , which is less than half the magnitude of the effects of bond market development in the originating country. In contrast to the role of bond markets, the development of equity markets in both the originating and destination countries exerts a positively significant effect on both debt and equity cross-border FPI holdings, with the magnitude of the coefficients being greater for equity than for debt.

We find that corporate accounting quality in the originating country promotes equity but not debt FPI, and that the same variable in the destination country is negatively signed and significant for both debt and equity FPI. This latter result is not intuitive, and we believe it stems from the lack of variation in the Bushman et al. (2004) measure across the countries in our sample. Investor protection in the originating country promotes equity holdings but not debt, while the same variable in the destination country positively impacts on both debt and equity holdings, with the coefficient being larger for equity than for debt. The level of country risk in both the 
originating and destination countries impacts negatively and significantly on cross-border holdings of both debt and equity ${ }^{10}$.

\subsection{FPI, gravity and culture}

Table 6 presents our estimates of equation (6) which contains the full set of cultural variables along with the significant gravity and institutional strength controls from the $\bar{G}^{i}$ and $\bar{I}^{i}$ vectors that appear in columns (3) and (6) of Table 5. For ease of presentation, we do not repeat the estimates of the $\bar{G}^{i}$ and $\bar{I}^{i}$ vectors in Table 6, with the exception of the geographic distance variable $\left(D_{i s t}{ }^{G e o}\right)$ which we continue to present for comparison purposes across all models. Table 6 here

Columns (1) and (4) replicate model (5), so the (Dist $\left.{ }^{G e o}\right)$ coefficients are the same as in columns (3) and (6) of Table 5. Columns (2) and (5) of Table 6 present our estimates of model (7). We can see that the multiplicative distance term is indeed negatively signed and strongly significant in both the debt and equity equations with coefficients of -0.02 and -0.03 in the debt and equity models respectively. This confirms that cultural distance does make geographical distance seem greater. Comparing columns (2) with (1) and (5) with (4) in Table 6, the (Dist ${ }^{G e o}$ ) coefficient $\alpha_{1}^{i}$ declines from -1.26 to -1.21 in the debt equation and from -0.99 to -0.90 in the equity equation, confirming our conjecture that cultural distance does some of the work attributed to geographic distance in gravity models of FPI. It is therefore interesting to now set the aggregate cultural distance parameter $\gamma_{1}^{i}=0$, and to include the individual components of cultural distance along with the national cultural characteristics of the originating and destination countries in our final parsimonious model (6).

Columns (3) and (6) present these results. As before, these models also contain the parsimonious sets of gravity and institutional strength controls that are presented in columns (3) 
and (6) of Table 5, but are not replicated here for ease of presentation. We first note that the geographical distance variable ( $D i s t^{G e o}$ ) remains negatively signed and strongly significant with coefficients of -1.27 and -0.93 for debt and equity, and that it rises marginally in both cases when we include the set of cultural variables. This provides evidence that these cultural variables are exerting influences that are independent from the basic gravity effects. This is consistent with Beugelsdijk and Frijns (2010) whose geographic distance variable also rises when cultural variables are added, and it is congruent with Hakanson and Ambos (2010) who note that psychic distance is conceptually distinct from cultural distance, and that without a more intensive analysis of the constituents of psychic distance, we would expect to find that cultural distance reduces the importance of geographical distance.

Examining next the role of common language (Clan), we find that it is positively signed and strongly significant, with coefficients of 0.65 for debt and 0.90 for equity. This result is contrary to Aviat and Coeurdacier (2007) who found it to be insignificant. Portes and Rey (2005) and Daude and Fratzscher (2006) found mixed results, with the latter's estimated coefficient for equity being significant at 0.6 and insignificant for debt. Our finding is consistent with Lane and Milesi-Ferretti (2008) and Beugelsdijk and Frijns (2010) who found common language to be significantly positive. Our result demonstrates that common language is indeed an important cultural determinant of both debt and equity holdings, and considerably greater for cross-border equity holdings than has been previously reported. This supports the importance of information flows through which equity investors can keep abreast of foreign company releases, market sentiment and media reports when they are presented in a common language.

Looking at the role of common religion $(\mathrm{Crel})$, it is interesting to note that this has not been previously investigated in research on gravity models of FPI in spite of the fact that religion and finance share deep-rooted relationships. The mediaeval conflicts between Christian teaching 
on usury and the growth of European banking, and the present-day requirements of Islamic finance in relation to interest bearing instruments are testament to this. In their study of financial market development, Stulz and Williamson (2003) concluded that civil law can explain equity market development, and religion can explain credit market development. We find that common religion is positively signed and strongly significant, with coefficients of 0.49 for debt and 0.63 for equity. In contrast to this, we find that common legal system origin (Cleg) is insignificant in both the debt and equity equations. The former is consistent with previous researchers who have found mixed results, but the latter is inconsistent with the estimates for equity reported by Daude and Fratzscher (2006), Aviat and Coeurdacier (2007) and Lane and Milesi-Ferretti (2008). It is possible that, as suggested by Guiso et al (2009), the strong role played by common religion interacts with the role of common legal system origin in ways that merit further research.

We next examine the individual components of cultural distance. Columns (3) and (6) of Table 6 show that distance in masculinity is positively signed and statistically significant in both the debt and equity equations with almost identical coefficients of 0.09 . Distance in the degree of individualism enters the debt equation with a significantly positive coefficient of 0.13 , but does not feature in the equity equation. Distance in the degree of power distance enters the debt equation with a significantly negative coefficient of -0.06 , while not featuring in the equity equation. Interestingly, distance in the degree of uncertainty avoidance does not feature in either the debt or equity equations. We shall return to this shortly.

We now examine the role of Hofstede's (2001) cultural identifiers in the originating and destination countries. Although most of these variables have not hitherto been investigated in the context of cross-border FPI holdings ${ }^{11}$, Table 6 shows that they have significant roles to play. Looking first at the degree of masculinity, De Jong and Semenov (2002) argue that this cultural identifier is synonymous with support for competitive processes and outcomes, and that it is 
associated with greater stock market depth. We find that the degree of masculinity in the originating country $\left(\mathrm{Masc}^{O C}\right)$ impacts positively on cross-border debt and equity holdings with coefficients of 0.58 and 0.22 . In the destination country $\left(\mathrm{Masc}^{D C}\right)$ also impacts positively and significantly in both equations with similar coefficient magnitudes of 0.41 and 0.51 for debt and equity. This implies that country A with a 10 percent higher measure of masculinity will tend to supply 6 percent more debt and 2 percent more equity to the international markets, and to hold about 4 percent more cross-border debt and 5 percent more cross-border equity assets than country B and vice versa. This is consistent with De Jong and Semenov (2002) and with Rothaermel, Kotha and Steensma (2006).

Looking next at the degree of individualism, Gleason, Mathur and Mathur (2000) argue from Hirshleifer and Thakor (1992) that cultures with high individualism tend to be associated with management taking riskier decisions in their desire for success rather than protecting shareholder value, and that this leads to less debt in corporate capital structures. If this carries over to FPI, high individualism should be associated with greater holdings of cross-border equity than debt. A similar finding emerges from the analysis of Rothaermel, Kotha and Steensma (2006). More recently, Chui, Titman and Wei (2010) link individualism to overconfidence that causes under-estimation of the risks associated with overseas investments, resulting in a lower home bias as confirmed by Beugelsdijk and Frijns (2010). Our findings confirm these results, and by examining this cultural trait in both the originating and destination countries, adds to our understanding. We find that the degree of individualism in the originating country $\left(\operatorname{Ind} v^{O C}\right)$ impacts positively on cross-border holdings of both debt and equity with coefficients of 0.61 and 1.79 respectively, and in the destination country $I n d v^{D C}$ impacts positively and significantly in both equations with similar coefficient magnitudes of 1.84 and 1.56 for debt and equity. It is noticeable that the effect of the degree of individualism in the originating country in the equity 
equation is almost three times that for the debt equation. Taking the combined effects of the degree of individualism in the originating and destination countries, the sum of the $I n d v^{O C}$ and Indv ${ }^{D C}$ coefficients in the debt and equity equations are 2.45 and 3.35 respectively. This implies that country A with a 10 percent higher measure of Hofstede's individualism index will tend to supply 6 percent more debt and 18 percent more equity assets to the international markets, and to hold 18 and 16 percent more cross-border debt and equity assets than country B and vice versa. This is consistent with an international capital structure version of the arguments proposed by Gleason, Mathur and Mathur (2000).

Considering the degree of power distance, the closest relevant research by Chui, Lloyd and Kwok (2002) finds that higher degrees of the Schwartz and Sagiv (1995) 'mastery' cultural dimension (which is interpretable as approximating Hofstede's power distance dimension) are associated with lower debt ratios. We obtain the strong result that in the originating country, Powd ${ }^{O C}$, impacts negatively on cross-border holdings of both debt and equity with coefficients of 0.69 and -0.04 respectively, and in the destination country, $P o w d^{D C}$ impacts positively and significantly in both equations with coefficients of 0.43 and 0.59 for debt and equity. This implies that country A with a 10 percent higher measure of power distance will tend to supply 7 percent less debt and under $1 / 2$ a percent less equity assets to the international markets, and to hold 4 and 6 percent more cross-border debt and equity assets than country B and vice versa. While consistent with Chui, Lloyd and Kwok (2002), our finding in relation to FPI applies more generally to both debt and equity assets across a wider sample of countries.

With regard to uncertainty avoidance, we obtain the strong result that this cultural identifier does not impact significantly on cross-border holdings of either debt or equity in either the originating or destination countries. This mirrors our finding with respect to the distance between countries on the uncertainty avoidance index. At first glance, this might seem counter- 
intuitive given the central concern of risk management in international portfolio choice.

Furthermore, De Jong and Semenov (2002) find that a cultural appetite for risk (which proxies for the inverse of Hofstede's uncertainty avoidance) is associated with greater stock market depth. Using the cultural measures of Schwartz and Sagiv (1995), however, Chui, Lloyd and Kwok (2002) find that higher degrees of 'conservatism' (which could approximate Hofstede's uncertainty avoidance) are associated with lower corporate debt ratios. In addition, Gleason Mathur and Mathur (2000) argue that because higher debt leads to greater risks of corporate bankruptcy, higher uncertainty avoidance should lead to lower levels of debt in corporate capital structures. Although Kirkman, Lowe and Gibson (2006) note that uncertainty avoidance is often the cultural attribute associated with economic exchange, Chui and Kwok (2008) suggest that home bias is congruent with higher levels of uncertainty avoidance, and this is confirmed by Beugelsdijk and Frijns (2010) who find that greater uncertainty avoidance leads to lower foreign equity investment by mutual funds.

We conclude that the cultural dimension of uncertainty avoidance applies to FPI in a different manner to corporate capital structure. Although higher uncertainty avoidance could lead to more debt than equity FPI holdings to mitigate any perceived greater risks and informational asymmetries associated with equity investments, a more internationally diversified portfolio generally reduces risk. It is also worth noting from Table 5 that the level of country risk in both the originating and destination countries impacts negatively and significantly on cross-border holdings of both debt and equity. The estimated coefficients for Risk ${ }^{O C}$ and Risk ${ }^{D C}$ imply that Country A with a 10 percent lower PRS measure of risk will tend to supply 7 percent more debt and equity assets to the international markets and to hold 5 percent and 4 percent more debt and equity assets. The question thus arises about the extent to which the cultural attitudes to risk avoidance exert impacts that act independently of the measured levels of risk. Future research 
might usefully consider cultural measures of uncertainty avoidance adjusted for the actual levels of country risk.

We can summarise our results using the variables in the Culture vector (3) as follows. First, controlling for an extensive set of institutional strength differences, the existence of common language and religion between countries exerts significantly positive effects on crossborder FPI holdings of both debt and equity that counteract the gravity forces of geographical distances. These effects are greater for cross-border equity than for debt holdings. Second, Hofstede's cultural identifiers of masculinity and power distance in both the originating and destination countries, along with the degree of individualism in destination countries, exert previously unrecognised influences on cross-border FPI holdings of debt and equity that are additional to the standard gravity and institutional strength variables. Third, in FPI destination countries, we find that higher degrees of individualism, masculinity and power distance tend to raise both foreign debt and equity holdings by very similar amounts. The magnitudes of their overall effects are the same insofar as the sum of the coefficients on $I n d v^{D C}, M a s c^{D C}$ and $P o w d^{D C}$ in the debt and equity equations are 2.69 and 2.66 respectively. Fourth, in FPI originating countries, Hofstede's cultural characteristics exert different impacts on cross-border debt and equity holdings. The degree of masculinity in originating countries, $\operatorname{Masc}^{O C}$, positively influences debt holdings more than twice as much as equity FPI, and the degree of individualism, $\operatorname{Ind} v^{O C}$, positively influences cross-border equity holdings almost three times as much as debt. By way of contrast, the degree of power distance in originating countries, $P o w d^{O C}$, has a greater effect on debt than on equity holdings. Finally, countries that are less risky in terms of their overall political, economic and financial performance tend to participate more fully in cross-border FPI holdings of both debt and equity, and this propensity to diversify internationally is not influenced by cultural attitudes to risk. Hofstede's uncertainty avoidance does not feature significantly in 
cross border holdings of debt or equity, and neither does cultural distance measured in terms of differences to risk avoidance.

\section{Summary and conclusions}

In this paper, we have generalised the set of cultural variables that has hitherto been incorporated within gravity models of foreign portfolio investment (FPI). Using the International Monetary Fund's (IMF) Coordinated Portfolio Investment Survey (CPIS) across 174 originating and 50 destination countries for the period 2001-2007, we conducted a series of panel estimates to clarify the roles and effects of three sets of variables: the standard gravity variables that proxy for transport and transaction costs; institutional strength and informational asymmetry variables; and cultural variables. We controlled for the standard gravity effects using the geographic distance between countries, economic growth differentials, financial market development, corporate accounting quality, investor protection and country risk. Our cultural variables included language; legal system origin; religion; Hofstede's (2001) individualism, masculinity, power distance and uncertainty avoidance; and Kogut and Singh's (1988) cultural distances based on each of Hofstede's cultural characteristics taken separately and together.

Our extended gravity models explain about 60 percent of the total variation in cross-border holdings of debt and equity. Controlling for the standard gravity and institutional strength variables, cross-border FPI patterns are significantly determined by the cultural characteristics of both the originating and destination countries as well as by the cultural distance between them. Culture and cultural distance operate alongside and additional to geographical distance in determining global FPI patterns. Amongst our main findings are that common language and religion between financial trading partners exerts significant positive effects on cross-border FPI holdings of both debt and equity that counteract the gravity forces of geographical distances, and 
these effects are greater for cross-border equity than debt holdings. In FPI destination countries, higher (lower) degrees of individuality, masculinity and power distance tend to raise (reduce) cross-border debt and equity holdings by similar amounts. In FPI originating countries, Hofstede's (2001) cultural characteristics exert different impacts on cross-border debt and equity holdings. The degree of masculinity in originating countries positively influences debt holdings more than twice as much as equity FPI, and the degree of individuality positively influences cross-border equity holdings almost three times as much as debt. By way of contrast, the degree of power distance in originating countries has a greater effect on debt than equity holdings. Finally, countries that are less risky in terms of their overall political, economic and financial performance tend to participate more fully in cross-border FPI holdings of both debt and equity, and this propensity to diversify internationally is not influenced by cultural attitudes to risk as measured by Hofstede's uncertainty avoidance.

Overall, our paper points to the insights that can be gained by clearly separating the measurement and effects of gravity and culture - gravity always deters FPI, and cultural differences can accentuate this deterrence, but aspects of culture can promote FPI. By clearly separating cultural effects from the standard gravity effects, our results are consistent with the need for a more completely conceived view of the role of culture in shaping the core belief systems and values of heterogeneous agents. This approach necessitates moving away from the representative agent framework, and advancing both theory and empirical work that more explicitly recognises how cultural differences lead to internationally heterogeneous agents with divergent beliefs, preferences and values. Adopting this research agenda make it clear that much remains to be done, but deep insights will surely follow. 


\section{Acknowledgements}

We wish to thank the editor and the reviewers for exceedingly useful feedback on the drafts of this paper, which have greatly improved it. In addition, we thank Elaine Hutson for extensive comments, Thomas Lagoarde-Segot for initial data assistance and collection, QuYu Zhang as well as participants in seminars at Trinity College Dublin and NUI-Maynooth. We thank the participants and reviewers at INFINITI June 2008, Academy of International Business June 2008, AIB- UK and Ireland June 2009, INFINITI June 2009, AIB June 2009, FMA October 2009 and FMA October 2010.

\section{References}

Aggarwal, R., Goodell, J.W., 2009a. Markets and institutions in financial intermediation: National characteristics as determinants. Journal of Banking and Finance 33, 1770-1780.

Aggarwal, R., Goodell, J.W., 2009b. Markets versus institutions in developing countries: National attributes as determinants. Emerging Markets Review 10, 51-66.

Anderson, J.E., 1979. A theoretical foundation for the gravity equation. American Economic Review 69, 106-116.

Anderson, J.E., 2000. Why do nations trade (so little)? Pacific Economic Review 5, 115-134. Aviat, A., Coeurdacier, N., 2007. The geography of trade in goods and asset holdings. Journal of International Economics 71, 22-51.

Bevan, A. A., Estrin, S., 2004. The determinants of foreign direct investment into European transition economies. Journal of Comparative Economics 32, 775-787.

Beugelsdijk, S., Frijns, B., 2010. A cultural explanation of the foreign bias in international asset allocation. Journal of Banking and Finance 34, 2121-2131. 
Bhamra, H.S., Uppal, R., 2010. Asset prices with heterogeneity in preferences and beliefs. Research paper, November.

Breiman, L., Freidman, J., Stone, C., Olshen, R., 1984. Classification and Regression Trees. Chapman and Hall/CRC, London.

Bushman, R.M., Piotroski, J.D., Smith, A.J., 2004. What determines corporate transparency? Journal of Accounting Research 42, 207-252.

Cairnes, J.E., 1874. Some Leading Principles of Political Economy Newly Expounded. Harper \& Brothers, London.

Cesarini, D., Johannesson, M., Lichtenstein, P., Sandwell, O. and Wallace, B., 2010. Genetic variation in financial decision making. The Journal of Finance 65, 1725-1754.

Chui, A.C.W., Kwok, C.C.Y., 2008. National culture and life insurance consumption. Journal of International Business Studies 39, 88-101.

Chui, A.C.W., Lloyd, A.E., Kwok, C.C.Y., 2002. The determination of capital structure: Is national culture a missing piece to the puzzle? Journal of International Business Studies 33, 99127.

Chui, A.C.W., Titman, S., Wei, K.C.J., 2010. Individualism and momentum around the world. The Journal of Finance 65, 361-392.

Cyert, R., March, J., 1953. A Behavioural Theory of the Firm. Prentice Hall, New Jersey. Daude, C., Fratzscher, M., 2006. The pecking order of cross-border investment. European Central Bank, Working Paper Series: 590, Frankfurt.

de Bondt, W., Forbes, W., Hamalainen, P., Muradoglu, Y.G., 2010. What can behavioural finance teach us about finance? Qualitative Research in Financial Markets 2, 29-36.

De Jong, E., Semenov, R., 2002. Cross-country differences in stock market development: A cultural view. Research paper, SSRN. 
Evenett, S.J., Keller, W., 2002. On theories explaining the success of the gravity equation. Journal of Political Economy 110, 281-316.

Feenstra, R.C., Markusen, J.R., Rose, A.K., 2001. Using the gravity equation to differentiate among alternative theories of trade. Canadian Journal of Economics 34, 430-447.

Flavin, T.J., Hurley, M.J., Rousseau, F., 2002. Explaining stock market correlation: A gravity model approach. Manchester School 70, 87-106.

Fratianni, M., 2007. The gravity equation in international trade, in: Rugman, A. (Ed.), Handbook of International Business, Oxford University Press, Oxford.

Ghemawat, P., 2001. Distance still matters: The hard reality of global expansion. Harvard Business Review 79, 137-147.

Gleason, K.C., Mathur, L.K., Mathur, I., 2000. The interrelationship between culture, capital structure and performance: Evidence from European retailers. Journal of Business Research 50, 185-191.

Gorodnichenko, Y., Roland, G., 2010. Culture, institutions and the wealth of nations, Research paper, SSRN eLibrary.

Graham, J.R., Harvey, C.R., Huang, H., 2009. Investor competence, trading frequency, and home bias. Management Science 55, 1094-1106.

Nobes, C.W., 1992. International Classification of Financial Reporting. Routledge, UK. Grinblatt, M. and Keloharju, M. 2001. How distance, language and culture influence stockholdings and trades. The Journal of Finance 56, 1053-1073.

Guiso, L., Sapienza, P., Zingales, L., 2009. Cultural biases in economic exchange. Quarterly Journal of Economics 124, 1095-1131.

Hakanson, L., Ambos, B., 2010. The antecedents of psychic distance. Journal of International Management 16, 195-210. 
Hansen, L.P., 2007. Beliefs, doubts and learning. American Economic Review 97, 1-30.

Hendry, D.F., 2000. Econometrics - Alchemy or Science? In: Hendry, D.F., Essays in

Econometric Methodology. Oxford University Press, Oxford and New York.

Hirshleifer, D., Thakor, A.V., 1992. Managerial conservatism, project choice, and debt. Review of Financial Studies 5, 437-470.

Hofstede, G., 2001. Culture's Consequences: Comparing Values, Behaviors, Institutions and Organizations across Nations. Sage, Thousand Oaks.

House, R., Javidan, M., Hanges, P., Dorfman, P., 2002. Understanding cultures and implicit leadership theories across the globe: An introduction to project GLOBE. Journal of World Business 37, 3-10.

Huang, R.R., 2007. Distance and trade: Disentangling unfamiliarity effects and transport cost effects. European Economic Review 51, 161-181.

Kirkman, B.L., Lowe, K.B., Gibson, C.B., 2006. A quarter century of culture's consequences: A review of empirical research incorporating Hofstede's cultural values framework. Journal of International Business Studies 37, 285-320.

Inglehart, R., 1997. Modernisation and Post-modernisation: Cultural, Economic and Political Change in 43 Societies. Princeton University Press, Princeton, NJ.

Kogut, B., Singh, H., 1988. The effect of national culture on the choice of entry mode. Journal of International Business Studies 19, 411-432.

Lane, P.R., Milesi-Ferretti, G.M., 2008. International investment patterns. Review of Economics and Statistics 90, 538-549.

Leamer, E. E., Storper, M., 2001. The economic geography of the internet age. Journal of International Business Studies 32, 641-665. 
Lewer, J.J., Van den Berg, H., 2007. Religion and international trade: Does the sharing of a religious culture facilitate the formation of trade networks? American Journal of Economics and Sociology 66, 765-794.

Lewis, K.K., 1999. Trying to explain home bias in equities and consumption. Journal of Economic Literature 37, 571-608.

Lucey, B.M., Zhang, Q., 2010. Does cultural distance matter in international stock market comovement? Evidence from emerging economies around the world. Emerging Markets Review $11,62-78$.

Maddox, J., Wilson, E., Quintan, A., Turner, J., Bowker, J., 1984. Genes, minds and culture. Zygon 19, 213-232.

Mulder, M., 1977. The Daily Power Game. Martinus Nijhoff, Amsterdam.

Newton, I., 1687. Philosophiae Naturalis Principia Mathematica. Royal Academy, London.

O'Grady, S., Lane, H.W., 1996. The psychic distance paradox. Journal of International Business Studies 27, 309-333.

Portes, R., Rey, H., 1998. The euro and international equity flows. Journal of the Japanese and International Economies 12, 406-423.

Portes, R., Rey, H., 2005. The determinants of cross-border equity flows. Journal of International Economics 65, 269-296.

Reus, T.H., Lamont, B.T., 2009. The double-edged sword of cultural distance in international acquisitions. Journal of International Business Studies 40, 1298-1316.

Ronen, S., Shenkar, O., 1985. Clustering countries on attitudinal dimensions: A review and synthesis. The Academy of Management Review 10, 435-454.

Rosati, S. and S. Secola (2006). Explaining cross-border large-value payment flows: Evidence from TARGET and EURO1 data. Journal of Banking \& Finance 30, 1753-1782. 
Rose, A. K. and M. M. Spiegel (2004). A gravity model of sovereign lending: Trade, default, and credit. IMF Staff Papers 51, 50-64.

Rothaermel, F.T., Kotha, S., Steensma, H.K., 2006. International market entry by U.S. internet firms: An empirical analysis of country risk, national culture, and market size. Journal of Management 32, 56-82.

Santos Silva, J.M.C., Tenreyro, S., 2006. The log of gravity. Review of Economics and Statistics $88,641-658$.

Schwartz, S.H., Sagiv, L., 1995. Identifying culture-specifics in the content and structure of values. Journal of Cross-Cultural Psychology 26, 92-116.

Senior, N., 1827. An introductory lecture on political economy. Speech delivered to the University of Oxford. J. Mawman, London.

Shefrin, H., 2001. Behavioural Finance: A Three-Volume Edited Collection. Edward Elgar, London.

Slangen, A.H.L., 2006. National cultural distance and initial foreign acquisition performance: The moderating effect of integration. Journal of World Business 41, 161-170.

Slangen, A.H.L, Beugelsdijk, S., 2010. The impact of institutional hazards on foreign multinational activity: A contingency perspective. Journal of International Business Studies 41, 980-995.

Stiglitz, J.E. 2010. An agenda for reforming economic theory. Slides presented to Institute for New Economic Thinking INET conference, 22 May, Cambridge.

Stein, E. and Daudo, C., 2007. Longitude matters: Time zones and the location of FDI, Journal of International Economics 71, 96-112.

Steinberg, S., Colla, D., 1995. CART: Tree-Structured Non-Parametric Data Analysis. Salford Systems, San Diego, CA. 
Stulz, R.M., Williamson, R., 2003. Culture, openness, and finance. Journal of Financial Economics 70, 313-349.

Taras, V., Rowney, J., Steel, P., 2009. Half a century of measuring culture: Review of approaches, challenges, and limitations based on the analysis of 121 instruments for quantifying culture. Journal of International Management 15, 357-373.

Thaler, R., 1993. Advances in Behavioural Finance. Russel Sage Foundation, New York. Tihanyi, L., Griffith, D.A., Russell, C.J., 2005. The effect of cultural distance on entry mode choice, international diversification, and MNE performance: A meta-analysis. Journal of International Business Studies 36, 270-83.

Tinbergen, J., 1962. Shaping the World Economy: Suggestions for an International Economic Policy. Twentieth Century Fund, New York.

Trefler, D., 1995. The case of the missing trade and other mysteries. American Economic Review $85,1029-1046$.

Tversky, A., Kahneman, D., 1974. Judgement and uncertainty: Heuristics and biases. Science 185, 1124-1131.

Zwinkels, R.C.J., Beugelsdijk, S. 2010. Gravity equations: Workhorse or Trojan horse in explaining trade and FDI patterns across time and space? International Business Review 19, 102115. 


\section{Table 1 \\ Data definitions and sources}

Dependent variable - debt: Portfolio equity instruments issued by originating country (OC) and held by destination country (DC) residents, in \$USm averaged over 2001- 2004. Source: IMF Coordinated Portfolio Investment Survey (CPIS), available at http:/www.imf.org/external/np/sta/pi/geo.htm.

Dependent variable - equity: Portfolio long term debt instruments issued by OC and held by DC residents, in \$USm averaged over 2001-2004. Source: as above.

Geographic distance (Dist ${ }^{G e o}$ ): Physical (great circle) distance in kilometres between the capital cities of country pairs. Source: CEPII, available at http://www.cepii.fr/anglaisgraph/bdd/distances.htm.

Economic growth (Grow): Arithmetic average of current price GDP growth over the 4-year period 2001-2004. Source: http://humandevelopment.bu.edu.

Bond market development (Bdev): The value of domestic debt securities in \$USm issued by financial institutions and corporations as a percentage of GDP. Source: Beck, Demirguc-Kent et al (2000), updated to 2004 .

Equity market capitalisation (Edev): The average value of equity market capitalization in \$USm over the period 2001-2004. Source: World Federation of Exchanges, http:/www.world-exchanges.org.

Corporate accounting quality (Accq): A composite index of overall disclosure quality and intensity, covering accounting and financial data in annual and periodic corporate communications. Source: Bushman, Piotroski et al. (2004), Appendix B.

Investor protection (Invp): The aggregate 'investor protection' index, an average of indices measuring transparency of transactions, liability for self-dealing, and shareholders' ability to sue officers and directors for misconduct. Source: Djankov, La Porta et al $2008 \mathrm{f}$

PRS measure of risk (Risk): A composite measure of economic, financial and political country risk, with higher (lower) scores indicating less (more) risk. Source: Political Risk Services, www.prsgroup.com.

Commonality of language (Clan): A dummy variable reflecting commonality of the major languages of country pairs, equal to 1 if there is commonality and 0 otherwise. Source: Rose and Spiegel (2004).

Commonality of legal system (Cleg): A dummy variable reflecting commonality of the legal origins of country pairs, equal to 1 if there is commonality and 0 otherwise. Source: Stulz and Williamson (2003) and Rose and Spiegel (2004).

Commonality of religion (Crel): A dummy variable reflecting commonality of the major religions of country pairs, equal to 1 if there is commonality and 0 otherwise. Source: Rose and Spiegel (2004).

K-S measure of cultural distance (Dist ${ }^{K S}$ ): A composite index of cultural distance constructed as per Kogut and Singh (1988) from the Hofstede indices. Source: our calculations.

Uncertainty avoidance index (Unca): The Hofstede measure. These data are widely available, see for example http://www.geert-hofstede.nl or Taras, Rowney and Steel (2009)

Power distance index (Powd): As above.

Masculinity index (Masc): As above.

Individualism index (Indv): As above. 
Table 2

Summary statistics

\begin{tabular}{lccccc}
\hline & & & Standard & & \\
Variables & Mean & Median & deviation & Skewness & Kurtosis \\
& & & & & \\
Debt & 3.799 & 3.146 & 3.839 & 0.418 & 1.790 \\
Equity & 3.761 & 3.428 & 3.748 & 0.328 & 1.925 \\
Geographic distance & 8.619 & 9.056 & 1.007 & -1.084 & 3.351 \\
Economic growth in OC & 4.08 & 3.67 & 2.06 & 0.70 & 2.83 \\
Economic growth in DC & 4.21 & 3.79 & 2.20 & 0.71 & 2.63 \\
Bond market development in OC & 0.413 & 0.355 & 0.273 & 1.649 & 6.153 \\
Bond market development in DC & 0.416 & 0.374 & 0.268 & 1.667 & 6.355 \\
Equity market capitalization in OC & 0.607 & 0.520 & 0.509 & 1.072 & 3.557 \\
Equity market capitalization in DC & 0.609 & 0.520 & 0.500 & 1.077 & 3.668 \\
Accounting quality in OC & 4.272 & 4.304 & 0.128 & -0.060 & 2.986 \\
Accounting quality in DC & 4.256 & 4.290 & 0.148 & -0.563 & 3.679 \\
Investor protection in OC & 1.757 & 1.792 & 0.285 & -0.569 & 3.132 \\
Investor protection in DC & 1.782 & 1.792 & 0.295 & -0.588 & 3.044 \\
Legal system origin in OC & 1.264 & 1.326 & 0.252 & -0.659 & 2.163 \\
Legal system origin in DC & 1.278 & 1.411 & 0.256 & -0.729 & 2.197 \\
PRS risk in OC & 2.308 & 2.379 & 0.165 & -1.755 & 5.961 \\
PRS risk in DC & 2.309 & 2.379 & 0.167 & -1.673 & 5.596 \\
K-S measure of cultural distance & 2.038 & 1.818 & 1.365 & 0.856 & 3.785 \\
KS distance masculinity & 2.327 & 0.898 & 3.208 & 2.297 & 9.960 \\
KS distance individualism & 1.900 & 0.992 & 2.200 & 1.448 & 4.647 \\
KS distance power distance & 1.954 & 0.962 & 2.596 & 2.383 & 10.070 \\
KS distance uncertainty avoidance & 1.969 & 1.023 & 2.473 & 2.158 & 9.138 \\
Masculinity index in OC & 3.781 & 4.025 & 0.640 & -1.870 & 6.082 \\
Masculinity index in DC & 3.784 & 3.989 & 0.627 & -1.915 & 6.346 \\
Individualism index in OC & 3.896 & 4.143 & 0.530 & -0.962 & 2.964 \\
Individualism index in DC & 3.866 & 4.007 & 0.540 & -0.833 & 2.642 \\
Power distance index in OC & 3.790 & 3.892 & 0.517 & -0.842 & 3.451 \\
Power distance index in DC & 3.812 & 3.912 & 0.515 & -0.910 & 3.538 \\
Uncertainty avoidance index in OC & 4.043 & 4.159 & 0.511 & -1.732 & 7.253 \\
Uncertainty avoidance index in DC & 4.096 & 4.159 & 0.383 & -0.527 & 2.548 \\
\hline & & & & &
\end{tabular}

Notes. All variables are defined, and sources are detailed in the text and in Table 1.

' $\mathrm{OC}$ ' and ' $\mathrm{DC}$ ' refer to the origin country and the destination country respectively. 
Table 3

Hofstede's cultural dimensions by country and group

\begin{tabular}{|c|c|c|c|c|}
\hline & Individualism & Masculinity & $\begin{array}{c}\text { Power } \\
\text { distance }\end{array}$ & $\begin{array}{c}\text { Uncertainty } \\
\text { avoidance }\end{array}$ \\
\hline \multicolumn{5}{|l|}{ Countries } \\
\hline Argentina & 3.829 & 4.025 & 3.892 & 4.454 \\
\hline Australia & 4.500 & 4.111 & 3.584 & 3.932 \\
\hline Austria & 4.007 & 4.369 & 2.398 & 4.248 \\
\hline Brazil & 3.638 & 3.892 & 4.234 & 4.331 \\
\hline Canada & 4.382 & 3.951 & 3.664 & 3.871 \\
\hline Colombia & 2.565 & 4.159 & 4.205 & 4.382 \\
\hline Denmark & 4.304 & 2.773 & 2.890 & 3.135 \\
\hline Finland & 4.143 & 3.258 & 3.497 & 4.078 \\
\hline France & 4.263 & 3.761 & 4.220 & 4.454 \\
\hline Germany & 4.205 & 4.190 & 3.555 & 4.174 \\
\hline Greece & 3.555 & 4.043 & 4.094 & 4.718 \\
\hline India & 3.871 & 4.025 & 4.344 & 3.689 \\
\hline Ireland & 4.248 & 4.220 & 3.332 & 3.555 \\
\hline Israel & 3.989 & 3.850 & 2.565 & 4.394 \\
\hline Italy & 4.331 & 4.248 & 3.912 & 4.317 \\
\hline Japan & 3.829 & 4.554 & 3.989 & 4.522 \\
\hline Malaysia & 3.258 & 3.912 & 4.644 & 3.584 \\
\hline Mexico & 3.401 & 4.234 & 4.394 & 4.407 \\
\hline Netherlands & 4.382 & 2.639 & 3.638 & 3.970 \\
\hline New Zealand & 4.369 & 4.060 & 3.091 & 3.892 \\
\hline Philippines & 3.466 & 4.159 & 4.543 & 3.784 \\
\hline Singapore & 2.996 & 3.871 & 4.304 & 2.079 \\
\hline South Africa & 4.174 & 4.143 & 3.892 & 3.892 \\
\hline Spain & 3.932 & 3.738 & 4.043 & 4.454 \\
\hline Sweden & 4.263 & 1.609 & 3.434 & 3.367 \\
\hline Switzerland & 4.220 & 4.248 & 3.526 & 4.060 \\
\hline Thailand & 2.996 & 3.526 & 4.159 & 4.159 \\
\hline Turkey & 3.611 & 3.807 & 4.190 & 4.443 \\
\hline United Kingdom & 4.489 & 4.190 & 3.555 & 3.555 \\
\hline United States & 4.511 & 4.127 & 3.689 & 3.829 \\
\hline \multicolumn{5}{|l|}{ Cultural grouping } \\
\hline Anglo & 4.418 & 4.110 & 3.488 & 3.773 \\
\hline Confucian Asia & 3.406 & 4.207 & 4.149 & 3.282 \\
\hline Eastern Europe & 3.555 & 4.043 & 4.094 & 4.718 \\
\hline Germanic Europe & 4.203 & 3.859 & 3.277 & 4.113 \\
\hline Latin America & 3.356 & 4.079 & 4.181 & 4.394 \\
\hline Latin Europe & 3.962 & 3.806 & 3.784 & 4.453 \\
\hline Middle East & 3.611 & 3.807 & 4.190 & 4.443 \\
\hline Nordic Europe & 4.237 & 2.549 & 3.270 & 3.523 \\
\hline South Asia & 3.398 & 3.906 & 4.423 & 3.804 \\
\hline Sub-Saharan Africa & 4.174 & 4.143 & 3.892 & 3.892 \\
\hline
\end{tabular}

Notes. The mean scores (with \% range) of the cultural groupings are $3.83(29 \%)$ for individualism, 3.85 (60\%) for masculinity, 3.85 (33\%) for power distance; and 4.0 (40\%) for uncertainty avoidance. Anglo includes Australia, Canada, Ireland, New Zealand, South Africa and the UK. Confucian Asian includes China, Hong Kong, Japan, Singapore, South Korea and Taiwan. Eastern European includes Albania, Georgia, Greece, Hungary, Kazakhstan, Poland, Russia and Slovenia. Germanic European includes Austria, Germany, the Netherlands and Switzerland. Latin European includes France, Israel, Italy, Portugal, Spain and Switzerland. Middle Eastern includes Egypt, Kuwait, Morocco, Qatar and Turkey. Nordic European includes Denmark, Finland and Sweden. South Asian includes India, Indonesia, Iran, Malaysia, the Philippines and Thailand. The Latin America and sub-Saharan African groupings are self evident. 
Table 4

Extreme gravity and cultural distances amongst 564 country pairs

\begin{tabular}{cccccc}
\hline Physical distances & $\begin{array}{c}\text { Km } \\
\left({ }^{\circ} 000\right)\end{array}$ & Cultural distances & KS & $\begin{array}{c}\text { Physical and cultural } \\
\text { distances }\end{array}$ & $\begin{array}{c}\text { Ln(Km) } \\
+ \\
\text { KS }\end{array}$ \\
\hline$(1)$ & $(2)$ & $(3)$ & $(4)$ & $(5)$ & $(6)$ \\
\hline
\end{tabular}

Panel A: Greatest distances between country pairs

\begin{tabular}{l|c|l|l|l|c|} 
New Zealand - Spain & 19.586 & Japan - Sweden & 7.909 & Japan - Sweden & 16.919 \\
Columbia - Malaysia & 19.098 & Denmark - Mexico & 6.298 & Denmark - Mexico & 15.459 \\
Brazil - Philippines & 18.396 & Austria - Malaysia & 5.754 & Austria - Malaysia & 14.904 \\
Australia - UK & 17.014 & Greece - Singapore & 5.054 & Greece - Singapore & 14.166 \\
& \multicolumn{2}{|c|}{ Portugal - UK } & 5.007 & Norway - Philippines & 13.930 \\
& & Norway - Philippines & 4.750 & Chile - UK & 13.787 \\
& & & Australia - Portugal & 13.750
\end{tabular}

Panel B: Least distances between country pairs

\begin{tabular}{l|l|l|l|l|l|} 
Belgium - Netherlands & 0.173 & Australia - US & 0.020 & Belgium - France & 5.693 \\
Malaysia - Singapore & 0.316 & Germany - Switzerland & 0.034 & Norway - Sweden & 6.238 \\
France - UK & 0.343 & Brazil - Turkey & 0.052 & Germany - Switzerland & 6.256 \\
Finland - Sweden & 0.398 & Netherlands - Norway & 0.105 & Ireland - UK & 6.315 \\
Denmark - Norway & 0.485 & Belgium - France & 0.124 & Canada - US & 6.431 \\
Germany - Switzerland & 0.504 & Chile - Portugal & 0.157 & Malaysia - Singapore & 6.568 \\
Canada - US & 0.548 & Argentina - Spain & 0.178 & Greece - Turkey & 6.772 \\
Greece - Turkey & 0.561 & Ireland - UK & 0.182 & Denmark - Netherlands & 7.051 \\
India - Pakistan & 0.683 & Denmark - Sweden & 0.188 & \\
& Germany - Italy & 0.202 & \\
& Malaysia - Philippines & 0.229 & \\
\hline
\end{tabular}

Notes. The Table presents examples of the greatest and least physical, cultural, and combined physical and cultural distances from the sample of 564 country pairs. The physical distances are measured in thousands of kilometres in column (2), the cultural distances in column (4) are Kogut -Singh measures, and the combined physical and cultural distances in column (6) are the addition of the logs of column (2) plus column (4, In Panel A, columns (1), (3) and (5) provide all unique country pairs, with no individual country repeated, in the 25 country pairs out of all 564 country pairs with the greatest distances. Likewise, columns (1), (3) and (5) of Panel B provide all unique country pairs, with no individual country repeated, in the 25 country pairs with the least distances. 
Figure 1

Gravity and cultural distance for 564 country pairs

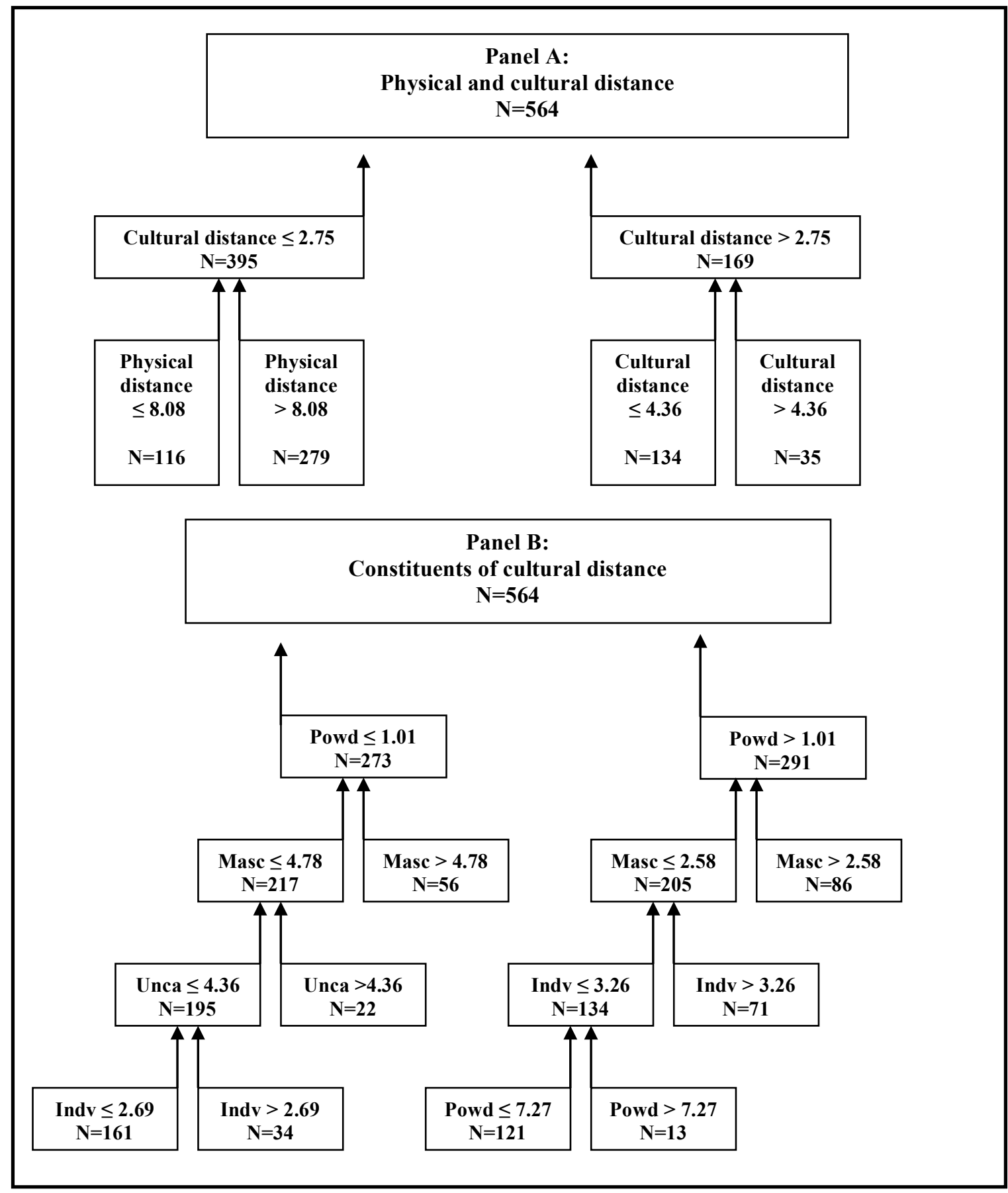

Notes: This Figure uses the Classification and Regression Tree (CART) software as described in the text to classify 564 country pairs on the dimensions of the physical and cultural distances that separate them. Panel A categorises overall distances (the sum of physical and cultural distance) into physical and cultural. Panel B categorises cultural distances into individualism (Indv), masculinity (Masc), power distance (Powd), and uncertainty avoidance (Unca) distances. 
Table 5

FPI, gravity and institutional strength

\begin{tabular}{|c|c|c|c|c|c|c|}
\hline & \multicolumn{3}{|c|}{ Debt } & \multicolumn{3}{|c|}{ Equity } \\
\hline & (1) & (2) & (3) & (4) & $(5)$ & (6) \\
\hline Geographic distance, Dist ${ }^{\mathrm{Geo}}$ & $\begin{array}{c}-1.906 \\
(.00)\end{array}$ & $\begin{array}{c}-1.900 \\
(.00)\end{array}$ & $\begin{array}{c}-1.264 \\
(.00)\end{array}$ & $\begin{array}{c}-1.656 \\
(.00)\end{array}$ & $\begin{array}{c}-1.672 \\
(.00)\end{array}$ & $\begin{array}{c}-0.987 \\
(.00)\end{array}$ \\
\hline Economic growth, Grow ${ }^{\mathrm{OC}}$ & & & & & $\begin{array}{c}0.030 \\
(.00)\end{array}$ & $\begin{array}{l}0.043 \\
(.00)\end{array}$ \\
\hline Economic growth, Grow ${ }^{\mathrm{DC}}$ & & & & & $\begin{array}{l}0.017 \\
(.03)\end{array}$ & $\begin{array}{l}0.018 \\
(.00)\end{array}$ \\
\hline Bond market development, Bdev ${ }^{\mathrm{OC}}$ & & & $\begin{array}{l}3.067 \\
(.00)\end{array}$ & & & $\begin{array}{l}2.016 \\
(.00)\end{array}$ \\
\hline Bond market development, $\mathrm{Bdev}^{\mathrm{DC}}$ & & & & & & $\begin{array}{l}0.730 \\
(.00)\end{array}$ \\
\hline Equity market development, Edev ${ }^{\mathrm{OC}}$ & & & $\begin{array}{l}1.305 \\
(.00)\end{array}$ & & & $\begin{array}{l}1.930 \\
(.00)\end{array}$ \\
\hline Equity market development, Edev ${ }^{\mathrm{DC}}$ & & & $\begin{array}{l}0.887 \\
(.00)\end{array}$ & & & $\begin{array}{l}1.700 \\
(.00)\end{array}$ \\
\hline Accounting quality, Accq ${ }^{\mathrm{OC}}$ & & & & & & $\begin{array}{l}1.852 \\
(.02)\end{array}$ \\
\hline Accounting quality, Accq ${ }^{\mathrm{DC}}$ & & & $\begin{array}{c}-4.153 \\
(.00)\end{array}$ & & & $\begin{array}{c}-3.179 \\
(.00)\end{array}$ \\
\hline Investor protection, Invp ${ }^{\mathrm{OC}}$ & & & & & & $\begin{array}{l}0.870 \\
(.00)\end{array}$ \\
\hline Investor protection, Invp ${ }^{D C}$ & & & $\begin{array}{l}0.561 \\
(.02)\end{array}$ & & & $\begin{array}{l}0.993 \\
(.00)\end{array}$ \\
\hline Country risk, Risk ${ }^{\mathrm{OC}}$ & & & $\begin{array}{c}-7.050 \\
(.00)\end{array}$ & & & $\begin{array}{c}-7.472 \\
(00)\end{array}$ \\
\hline Country risk, Risk ${ }^{\mathrm{DC}}$ & & & $\begin{array}{l}-5.283 \\
(.00)\end{array}$ & & & $\begin{array}{c}-4.052 \\
(.00)\end{array}$ \\
\hline$R^{2}$ & .25 & .25 & .52 & .19 & .20 & .54 \\
\hline
\end{tabular}

Notes. Definitions and sources of all variables and data sources are provided in Table 1. Superscripts 'OC' and ' $\mathrm{DC}$ ' denote, respectively, originating and destination country. All regressions are performed on 7,980 observations of annual data over the period 2001-2007 using OLS with White-corrected standard errors to allow for heteroscedasticity. 
Table 6

FPI, gravity, culture and cultural distance

\begin{tabular}{|c|c|c|c|c|c|c|}
\hline & \multicolumn{3}{|c|}{ Debt } & \multicolumn{3}{|c|}{ Equity } \\
\hline & (1) & (2) & (3) & (5) & (6) & (7) \\
\hline Geographic distance, Dist ${ }^{\text {Geo }}$ & $\begin{array}{c}-1.264 \\
(.00)\end{array}$ & $\begin{array}{c}-1.209 \\
(.00)\end{array}$ & $\begin{array}{c}-1.271 \\
(.00)\end{array}$ & $\begin{array}{c}-0.987 \\
(.00)\end{array}$ & $\begin{array}{c}-0.904 \\
(.00)\end{array}$ & $\begin{array}{c}-0.929 \\
(.00)\end{array}$ \\
\hline Geographic and cultural distance, Dist ${ }^{\mathrm{Ge} 0} * \mathbf{D i s t}^{\mathrm{KS}}$ & & $\begin{array}{c}-0.017 \\
(.00)\end{array}$ & & & $\begin{array}{c}-0.026 \\
(.00)\end{array}$ & \\
\hline Distance in masculinity, Dist ${ }^{\text {Masc }}$ & & & $\begin{array}{l}0.094 \\
(.00)\end{array}$ & & & $\begin{array}{l}0.095 \\
(.00)\end{array}$ \\
\hline Distance in individualism, Dist ${ }^{\text {Indv }}$ & & & $\begin{array}{l}0.132 \\
(.00)\end{array}$ & & & \\
\hline Distance in power distance, Dist $^{\text {Powd }}$ & & & $\begin{array}{c}-0.063 \\
(.00)\end{array}$ & & & \\
\hline Common language, Clan & & & $\begin{array}{l}0.651 \\
(.01)\end{array}$ & & & $\begin{array}{l}0.897 \\
(.00)\end{array}$ \\
\hline Common religion, Crel & & & $\begin{array}{l}0.488 \\
(.00)\end{array}$ & & & $\begin{array}{l}0.628 \\
(.00)\end{array}$ \\
\hline Masculinity, Masc ${ }^{\text {OC }}$ & & & $\begin{array}{c}0.578 \\
(.00)\end{array}$ & & & $\begin{array}{c}0.222 \\
(.03)\end{array}$ \\
\hline Masculinity, Masc $^{\text {DC }}$ & & & $\begin{array}{l}0.414 \\
(.00)\end{array}$ & & & $\begin{array}{c}0.513 \\
(.00)\end{array}$ \\
\hline Individualism, Indv ${ }^{\text {OC }}$ & & & $\begin{array}{l}0.607 \\
(.00)\end{array}$ & & & $\begin{array}{l}1.787 \\
(.00)\end{array}$ \\
\hline Individualism, Indv ${ }^{\mathbf{D C}}$ & & & $\begin{array}{l}1.842 \\
(.00)\end{array}$ & & & $\begin{array}{l}1.563 \\
(.00)\end{array}$ \\
\hline Power distance, Powd $^{\text {OC }}$ & & & $\begin{array}{c}-0.695 \\
(.00)\end{array}$ & & & $\begin{array}{c}-0.036 \\
(.01)\end{array}$ \\
\hline Power distance, Powd ${ }^{\mathrm{DC}}$ & & & $\begin{array}{l}0.434 \\
(.00)\end{array}$ & & & $\begin{array}{c}0.587 \\
(.00)\end{array}$ \\
\hline$R^{2}$ & .52 & .52 & .58 & .54 & .55 & .63 \\
\hline
\end{tabular}

Notes. Definitions of all variables and data sources are provided in Table 1. All regressions are performed on annual 2001-2007 data using random effects GLS with White-corrected standard errors. Columns (1) and (4) present the Dist ${ }^{G e o}$ parameter estimates from the parsimonious estimates of equation (5), copied from columns (3) and (6) in Table 5 for ease of comparison. Columns (2) and (5) present the $\gamma_{1}^{i}$ parameter estimates on the Dist ${ }^{G e o} *$ Dist ${ }^{K S}$ variable in equation (7). Columns (3) and (6) present the parsimonious estimates of the cultural parameters in equation (6). In these columns, the parsimonious estimates of the $\overline{\mathrm{G}}^{\mathrm{i}}$ and $\overline{\mathrm{I}}^{\mathrm{i}}$ vectors from columns (3) and (6) in Table 5 are not repeated for ease of exposition. 


\section{Endnotes}

${ }^{1}$ The gravitational force between two bodies was described by Newton (1687) as a constant times the product of their masses divided by the square root of the distance between them. Tinbergen (1962) first applied the gravity model to international commodity trade, and Anderson (1979) showed how it can be derived from trade theory.

${ }^{2}$ See, for, example, Feenstra, Markusen and Rose (2001), Evenett and Keller (2002), Santos Silva and Tenreyro (2006) and Fratianni (2007).

${ }^{3}$ See, inter alia, Ghemawat (2001), Leamer and Storper (2001), Bevan and Estrin (2004), Tihanyi, Griffith and Russell (2005), Slangen (2006), Stein and Daudo (2007), Reus and Lamont (2009) and Slangen and Beugelsdijk (2010). Zwinkels and Beugelsdijk (2010) provide an authoritative overview of the gravity model in international business research.

${ }^{4}$ See Portes and Rey (1998, 2005), Grinblatt and Keloharju (2001), Flavin, Hurley and Rousseau (2002), Rose and Spiegel (2004), Daude and Fratzscher (2006), Rosati and Secola (2006), Aviat and Coeurdacier (2007), Lane and Milesi-Ferretti (2008), Guiso, Sapienza and Zingales (2009), Reus and Lamont (2009), Beugelsdijk and Frijns (2010), and Lucey and Zhang (2010).

${ }^{5}$ These included American Samoa, British Indian Ocean Territory, Christmas Island, Falkland Islands (Malvinas) , French Southern Antarctic territories, Gaza Strip, Greenland, International organizations, Norfolk Island, Other countries (confidential data), Other countries (unallocated), Pitcairn, Timor-Leste, Tokelau, Tuvalu, United States Minor Outlying Islands, United States Minor Outlying Islands, Vatican City, Virgin Islands, British, Virgin Islands, and the West Bank.

${ }^{6}$ Aruba, The Bahamas, Bahrain, Bermuda, The Cayman Islands, Cyprus, Guernsey, The Isle of Man, Jersey, Lebanon, Luxembourg, Macao SAR, Malta, Mauritius, the Netherlands Antilles, Panama, and Vanuatu. 
${ }^{7}$ There are some data collection and definitional problems with the CPIS, discussed by Lane and MilesiFerretti (2008), section IV. These are not generally perceived to be severe.

${ }^{8}$ A fifth dimension, long-term orientation, has recently been added. It is, however, not yet as widely collected or as robustly analysed as the other four.

${ }^{9}$ In some cases (e.g., China) the capital city and the city with greatest financial depth and power are not the same. For consistency across all bilateral pairs, we hold to the capital-capital distance.

${ }^{10}$ The PRS measure or risk ranks the lowest risk countries with higher scores, and we have reversed the sign on the coefficient to reflect this.

${ }^{11}$ Beugelsdijk and Frijns (2010) include the degree of individualism and uncertainty avoidance in the home country along with Kogut-Singh cultural distance in their analysis of mutual fund cross-border equity holdings. 